\title{
IMPROVING CORROSION RESISTANCE OF MAGNESIUM ALLOY
}

\section{FOR AEROSPACE APPLICATIONS}

\author{
R. VISWANATHAN ${ }^{1}$, N. SIVASHANKAR ${ }^{2}$, S. CHANDRAKUMAR ${ }^{2} \&$ R. KARTHIK $^{2}$ \\ ${ }^{1}$ Assistant Professor, Department of Mechanical Engineering, Swami Vivekananda \\ Institute of Technology, Secunderabad, Telangana, India \\ ${ }^{2}$ Assistant Professor, Department of Mechanical Engineering, Kongunadu College \\ of Engineering and Technology, Trichy, Tamil Nadu, India
}

\begin{abstract}
Magnesium alloys are promising lightweight structural materials for both automotive and aerospace applications. Recently, magnesium (Mg) alloys have been attracted as biodegradable implants. However, one major drawback preventing the wide application is their inadequate corrosion performance. Modifying material surfaces with a coating layer is an effective means to control degradation, and biocompatibility. In this work aimed to improve the corrosion resistance on AZ31B Magnesium alloy by chromium electroplating process.
\end{abstract}

KEYWORDS: Magnesium Alloy, Chromium, Coating \& Electroplating

Received: Mar 18, 2019; Accepted: Apr 08, 2019; Published: May 13, 2019; Paper Id.: IJMPERDJUN201986

\section{INTRODUCTION}

Magnesium alloys possess the lowest density high specific strength, excellent castability and good machinability compared with other metallic constructional materials and has excellent physical and mechanical properties (Mordike et al., $2001 \&$ Ferragut et al., 2010). They are appropriate for the partial replacement of aluminium alloys for automotive industry, computer parts, aerospace industry and cellular phones where mass reduction is concerned. This might imply non-negligible weight and fuel savings in the aeronautical sector. Unfortunately, Mg alloys are also very susceptible to corrosion, do not resist wear and are greatly chemically reactive (Zhou et al., 2008). Other metals, such as aluminium and lithium, have been added to pure magnesium to decrease its shortcomings (Ardelean et al., 2008), which limit the use of magnesium and its alloys for computer parts and in the aerospace and the automotive industries (Zhao et al., 2006).

Biocompatible magnesium alloys offer great potential as absorbable implant materials. They degrade within a certain time span after surgery and are therefore suitable to temporarily accomplish medical functions, for instance as bone screws or plates (Denkena and Lucas 2007)

The main disadvantages of $\mathrm{Mg}$ and its alloys that hinder its extensive usage are poor corrosion and wear resistance and poor mechanical properties other than the strength. Although considerable progress has been achieved in developing advanced $\mathrm{Mg}$ alloys and composites with improved mechanical properties, their poor aqueous and galvanic corrosion resistance remains a danger (W.H. Sillekens, N. Hort 2013).

Chromium coatings have been in widespread use to enhance the high-temperature oxidation resistance of 
low-alloy steels since the 1950s. In this study, AZ31 is selected as the Mg alloy substrate due to its suitable physical and mechanical properties for automotive and aerospace sectors.

Chang et al. 2016 investigated a novel silicone penetrant pretreatment for forming a chromium-free conversion coating on AZ91D alloy. The pretreatment of silicone penetrant was found to be effective to prevent surface cracking of the conversion coating and improved the corrosion resistance of the alloy significantly.

Yang et al 2008 was conducted experiment of hydroxyapatite (Ca10 (PO4)6(OH) 2) coating on magnesium alloy, by ion-beam assisted deposition (IBAD) and heat treatment. It was found the coatings can decrease degradation rate of original $\mathrm{Mg}$ alloy significantly.

Frayret et al 2017 studied the chromium conversion coating on magnesium alloy. They found that final layer of chromium (III) oxide and magnesium hydroxide composes the coating allowing the protective properties. Alternative conversion coatings are based onto solutions containing chromium (III), permanganate, phosphates, Rare Earth Elements (REEs) or vanadium. Also it was discussed about the deposition and the protection mechanisms of these promising processes of CrVI substitution. Among them, permanganate/phosphate-based coating presents a better corrosion resistance than CCC and REEs have very efficient self-healing properties.

Magnesium is classified as a difficult to plate metal due to its high reactivity. It means that in the presence of air magnesium very quickly forms a passive oxide layer that must be removed prior to metal plating. The rapid formation of the oxide layer necessitates an appropriate pretreatment of the surface to introduce a surface layer that prevents oxidation but which can easily be removed during the plating process (Gray \& Luan 2001).

\section{EXPERIMENTAL WORK}

The work material of AZ31B Magnesium alloy was purchased from Exclusive Magnesium PVt. Ltd and its size are 135 x 135x $25 \mathrm{~mm}$. the Figure 1 shows the purchased Magnesium alloy bar for experimental work.

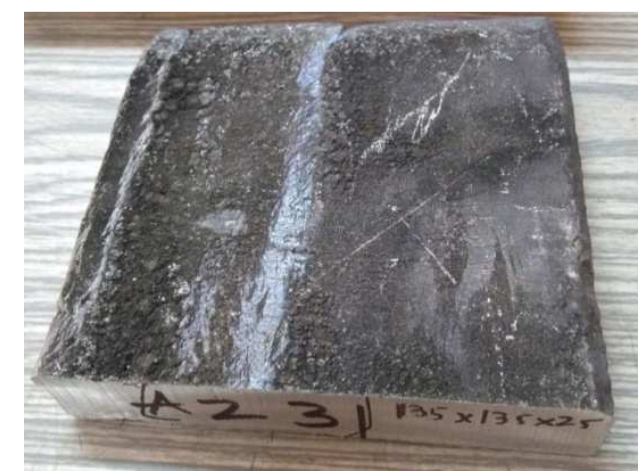

Figure 1: AZ31B Magnesium Alloy

\subsection{Mechanical Properties}

Table 1: Mechanical Properties of AZ31B Magnesium Alloy

\begin{tabular}{|l|c|}
\hline Elongation at break ( \% ) & 15 \\
\hline Hardness - Brinell (500 kg load, 10 mm ball) & 49 \\
\hline Modulus of elasticity ( GPa ) & 45 \\
\hline Tensile strength ( MPa ) & 270 \\
\hline Poisson's ratio & 0.29 \\
\hline
\end{tabular}




\subsection{Electroplating}

Electroplating is a process that uses an electric current to reduce dissolved metal cautions so that they form a thin coherent metal coating on an electrode. The term is also used for electrical oxidation of anions on to a solid substrate, as in the formation of silver chloride on silver wire to make silver/silver-chloride electrodes.

A process used to apply a coating, via electrolysis, from an electrically conductive base material to the object to be coated. Often used to silver plate cutlery and other decorative objects.

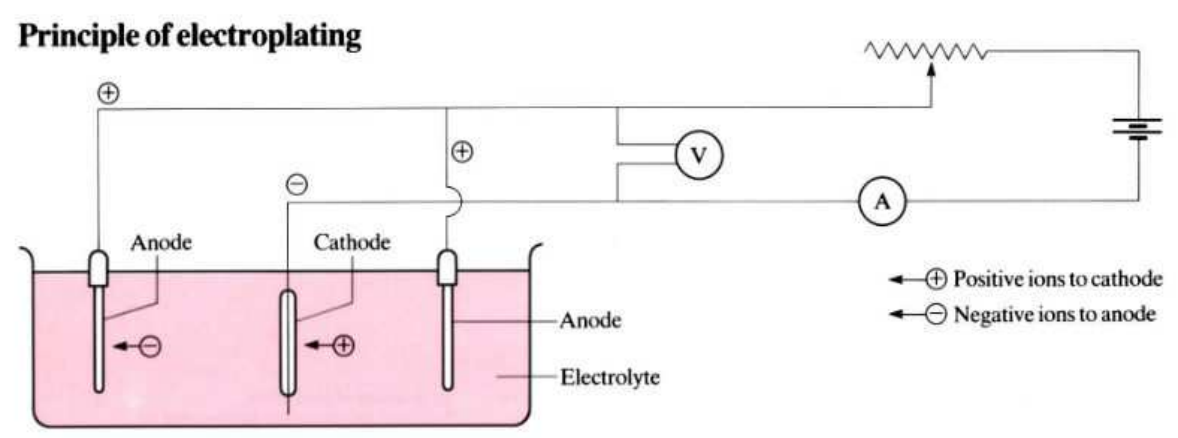

Figure 2: Working Principle of Electroplating

\subsection{Electroplating Bath}

In electroplating baths, connect the positive to one electrode (anode) and the negative to another electrode (cathode), place them both in a vessel of conducting fluid (water + salts) and anions (+ve ions) will be attracted to the cathode where they can pick up electrons as they deposit themselves. The anions can be placed in the conducting fluid (electrolyte) or they can be driven from the anode by the power source. The +ve ions are usually metal and thus coat the cathode in a layer of metal atoms.

\subsubsection{Electroplating Bath Process}

The electroplating bath step processes are three they are

- Acetone

- Magnesium nitride

- Chromium hard coating

\subsubsection{Acetone}

Acetone is the organic compound with the formula $\left(\mathrm{CH}_{3}\right)_{2} \mathrm{CO}$ It is a colourless, volatile, flammable liquid and is the simplest and smallest ketone. Acetone is miscible with water and serves as an important solvent, typically for cleaning purposes in laboratories.

\subsubsection{Magnesium Nitride}

Magnesium nitride $\left(\mathrm{Mg}_{3} \mathrm{~N}_{2}\right)$ is an inorganic compound of magnesium and nitrogen. Magnesium nitride reacts with water to produce magnesium hydroxide and ammonia gas, as do many metal nitrides. 


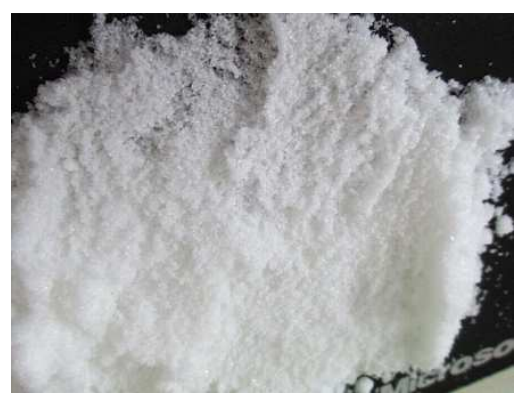

Figure 3: Magnesium Nitride

\subsubsection{Chromium}

Chromium is a chemical element. It is a steely-grey, lustrous, hard and brittle transition metal Chromium boasts a high usage rate as a metal that can be highly polished while resisting tarnishing. Chromium metal is of high value for its high corrosion resistance and hardness.

\subsection{Experimental Process}

The Electroplating process of magnesium alloys against corrosion uses chromium baths. This process requests an early pre-treatment to attain a high-performance coating. This step is necessary for preparing the surface to encourage the anchorage of the protective coating in the treatment bath. Then, the electroplating bath is responsible for a strong attack of the alloy surface to enhance the roughness of the surface to facilitate improve adhesion. The chromic acid-pickling bath initiates the chromate coating deposition (thin layer) at the centre of the magnesium grains. The Figure.4 Shows the electroplating of chromium on AZ31B Magnesium alloy. The hardness test was conducted on chromium coated work material and it was observed that hardness was improved slightly from 48 to 51BHN.

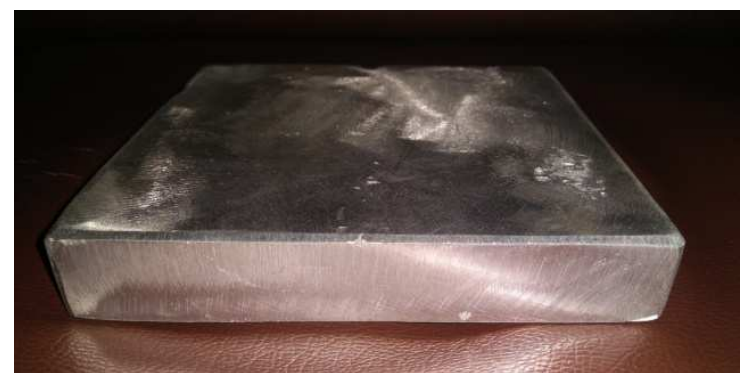

Figure 4: Magnesium Alloy after Chromium Coating

Table 2: Hardness Test Results

\begin{tabular}{|c|c|c|c|}
\hline \multirow{2}{*}{ S.No } & \multirow{2}{*}{ Work Load } & \multicolumn{2}{|c|}{ Brinell Hardness Value } \\
\cline { 3 - 4 } & & Before Coating & After Coating \\
\hline 1. & $500 \mathrm{~kg}, 10 \mathrm{~mm}$ Ball & $49 \mathrm{BHN}$ & $53 \mathrm{BHN}$ \\
\hline
\end{tabular}

\section{CONCLUSIONS}

The aim of this research work is chromium coating on magnesium alloy by an electroplating method for automotive and aerospace application. Chromium coating is partially completed in this work because path solutions are formed as foam and came out from electroplating path. The hardness test was conducted on the magnesium alloy after coating. It was observed that hardness of magnesium alloy was slightly improved. It was found that, necessary precautions will be required while coating on magnesium alloy through electroplating process. 


\section{ACKNOWLEDGEMENTS}

The author would like to thank the Silver Crown Metal Coatings, Coimbatore, India for providing facility to conduct this research work.

\section{REFERENCES}

1. Ardelean, H., Frateur, I., \& Marcus, P., (2008) Corrosion protection of magnesium alloys by cerium, zirconium and niobiumbased conversion coatings, Corrosion Science, 50, 1907- 1918.

2. Chang, S.H., Niu, L., Su, Y., Wang, W., Tong, X., \& Li, G., (2016) Effect of the pretreatment of silicone penetrant on the performance of the chromium-free chemfilm coated on AZ91D Mg alloys, Mater. Chem. Phy. 171, 312- 317.

3. Denkena, B., \& Lucas, A., (2007) Biocompatible Magnesium Alloys as Absorbable Implant Materials - Adjusted Surface and Subsurface Properties by Machining Processes, Annals of the CIRP Vol. 56/1/2007.

4. Ferragut, R., Moia, F., Fiori, F., Lussana, D., \& Riontino, G., (2010) Small-angle X-ray scattering study of the early stages of precipitation in a Mg-Nd-Gd (EV31) alloy, Journal of Alloys and Compounds, 495, 408-411.

5. Frayret, J., Dupin J.C., \& Pommiers, S., (2017) Corrosion Protection of Magnesium Alloys: From Chromium VI Process to Alternative Coatings Technologies, Magnesium Alloys, Chapter 6, pp.161-187.

6. Gray, J.E., \& Luan, B., (2002), Protective coatings on magnesium and its alloys - a critical review Journal of Alloys and Compounds, 336, 88-113.

7. Mordike, B.L., Ebert, T., (2001), Magnesium: properties - applications - potential, Materials Science and Engineering: A, $302,37-45$.

8. Sillekens, W.H., \& Hort, N., (2013) Magnesium and magnesium alloys, in Structural materials and processes in transportation, D. Lehmhus, M. Busse, A.S. Herrmann, K. Kayvantash (Ed.), Wiley-VCH.

9. El Keriem, M. S. A. B. D. Gamma Irradiation Effects On Doped Magnesium Borates Studied By Positron Annihilation Technique.

10. Sitepu, H., \& Al-Ghamdi, R. A. Application of the Rietveld Method to the Analysis of XRD Data of Corrosion Deposits Formed in Equipment Parts of Refineries and Gas Plants. IMPACT: International Journal of Research in Engineering \& Technology, $\operatorname{ISSN}(P): 2347-4599 ; \operatorname{ISSN}(E): 2321,8843,67-78$.

11. Yang, J.X., .Jiao, Y.P., CuiaIn-SeopLee, F.Z., Yin, Q.S., \& Zhang, Y., (2008) Modification of degradation behaviour of magnesium alloy by IBAD coating of calcium phosphate. Surface and Coatings Technology, Vol. 202, (22-23), 5733-5736.

12. Zhao, M., Wu, S., Luo, J., Fukuda, Y., \& H. Nakae, (2006) A chromium-free conversion coating of magnesium alloy by a phosphate-permanganate solution, Surface and Coatings Technology, 200 5407-5412.

13. Zhou, W., Shan, D., Han, E.H., \& Ke, W., (2008) Structure and formation mechanism of phosphate conversion coating on diecast AZ91D magnesium alloy, Corrosion Science, 50, 329-337. 
